\title{
El saber climatológico de los jesuitas en la América española. Siglo XVIII
}

\author{
por \\ Juan Alberto Molina García \\ Universidad Politécnica de Madrid
}

Los jesuitas se instalaron en el Nuevo Mundo desde su descubrimiento, participaron en tareas relacionadas con la investigación geográfica y natural y se interesaron por las descripciones, comparaciones y alabanzas de los climas americanos. En este sentido, emprendieron una serie de actuaciones encaminadas a la obtención, manejo y difusión de información climática que se basaban en la observación directa de los fenómenos, el seguimiento de modelos literarios de reconocido prestigio y la propia comunicación interna.

Palabras Clave: clima; información climática; jesuitas; observaciones cualitativas y cuantitativas; historias naturales y morales.

\section{INTRODUCCIÓN}

Durante el siglo XVIII, el Imperio español alcanzó una gran extensión y la Iglesia afianzó su presencia en él. Dado lo intrincado y voluminoso de los asuntos que era preciso atender con vistas a la buena administración política y religiosa de los territorios de la Corona, obtener cualquier tipo de información relevante suponía la entrada en escena de muchos actores implicados en la toma, registro, análisis, transmisión, comparación y publicación de múltiples y variados datos. Esto conllevaba el empleo de técnicas normalizadas de investigación y protocolos homogéneos de trabajo que contaban con referentes en Europa y el Nuevo Mundo. Dichas técnicas y protocolos eran de gran utilidad para adquirir conocimientos consensuados y reproducir experiencias, así como para comparar datos entre sí y encontrar regularidades ${ }^{1}$. De este

1 Valverde Pérez, 2007: 55-132. Guijarro Mora y González de la Lastra, 2010: 179-228. 
modo, los ilustrados adquirieron un sólido conocimiento en aspectos relativos a la diversidad natural, geográfica, sanitaria, etnográfica, cultural, política y administrativa de las posesiones españolas. Como prueban algunos estudios contemporáneos, el ambientalismo de la época relacionaba dichos aspectos con el clima ${ }^{2}$.

En este acontecer se vio comprometida la Compañía de Jesús. Sus miembros, en general, gozaron de una buena formación académica y tuvieron una profunda vocación misionera. De hecho, los candidatos a ser admitidos en la orden debían someterse a un largo y riguroso período de formación ascética e intelectual en el que asumían los valores espirituales e intelectuales y las metas establecidas por San Ignacio de Loyola. Es más, la educación avanzada y la disciplina ocuparon un lugar preeminente en el ideario fundacional de la congregación, pues a través de ellas se podrían llevar a cabo multitud de asuntos prácticos y se alcanzaría la perfección e incluso la salvación. Por esto, los jesuitas supieron adaptarse a las nuevas tendencias de la ciencia experimental europea e intervinieron por encargo de sus superiores y de entidades estatales en la recopilación y tratamiento de datos de diverso signo ${ }^{3}$. La información que así adquirieron, entre la cual se encontraba la referente a los climas, se transmitió de forma ordenada y jerárquica, siguiendo determinados canales comunicativos y poniéndola a disposición de las autoridades civiles y religiosas.

Hasta el presente se han publicado varios trabajos sobre la influencia del pensamiento religioso en las concepciones ilustradas de la naturaleza y la pérdida de literalidad de las interpretaciones bíblicas ${ }^{4}$. Existen, además, estudios sobre la cultura corporativa de la Compañía de Jesús y el interés de sus miembros por las humanidades y las ciencias; dichos estudios muestran el empeño de los religiosos en hacer circular información geográfica, natural y etnográfica en el seno de la orden ${ }^{5}$. También se ha escrito sobre la historia de la Iglesia en Iberoamérica ${ }^{6}$, la existencia de tres tradiciones científicas -metropolitana, virreinal y eclesiástica ${ }^{7}$ - en el mundo hispánico durante el período colonial y las polémicas generadas en torno a la naturaleza y la cultura del

2 Broc, 1971. Sargent, 1982. Iglesias, 1984: 202-217. Urteaga, 1992. Glacken, 1967. Capel, 1998-1999: 79-105.

3 Harris, 1989: 29-65; 1996: 287-318; 1999: 212-240. Ledezma y Millones Figueroa, 2005: 9-26.

4 Capel, 1983. Glacken, 1967.

5 Harris, 1996: 287-318. O’Malley, 1999. Tietz, 2001. Feingold, 2003. Millones Figueroa y Ledezma, 2005.

${ }^{6}$ Egaña, 1966.

7 Lafuente y López-Ocón Cabrera, 1996: 247-281. 
nuevo continente ${ }^{8}$. De forma particular, algunos autores han tratado aspectos relacionados con la labor científica y cultural de la Compañía de Jesús en el virreinato del Río de la Plata9 ${ }^{9}$, así como el sentimiento patriótico despertado entre los criollos a raíz de los estudios jesuíticos sobre la naturaleza y la cultura novohispanas ${ }^{10}$.

En este artículo se pone de manifiesto que una parte significativa del saber climatológico practicado en la América española durante el siglo XVIII corrió a cargo de los jesuitas. Para contextualizar debidamente el marco religioso y corporativo en el que transcurrió aquel saber, se estudian los fines perseguidos por los miembros de la congregación y se añaden algunos detalles sobre las aplicaciones prácticas de los hallazgos obtenidos. El texto incluye explicaciones sobre los procedimientos de indagación climatológica, la persistencia de dichos procedimientos a lo largo del tiempo y las novedades introducidas; en relación con esto, se especifica el carácter de las observaciones efectuadas por los actores involucrados. Los detalles acerca de las formas y canales de transmisión de información climática, los géneros literarios más usuales para organizarla y publicarla y los idiomas empleados al efecto ocupan un lugar destacado. En fin, no podían dejarse de lado los contenidos climatológicos específicos de las producciones escritas. Con todo ello se pretende alcanzar una idea precisa acerca de cómo la Compañía de Jesús ordenó, explicó y transmitió el saber climatológico en el mundo hispánico ilustrado. Para lograr ese objetivo, se ha recurrido al análisis y comentario de fuentes primarias y secundarias.

\section{ANTECEDENTES}

La Compañía de Jesús fue una institución religiosa de carácter elitista, disciplinada, jerárquica, bien organizada y dedicada a promulgar la fe cristiana. Los valores espirituales de la congregación, sustentados en la experiencia y en la racionalidad, impregnaron fuertemente la selección y la producción de ciertas formas de la ciencia moderna que fueron consideradas legítimas y valiosas por los priores. A su vez, la práctica científica de los jesuitas era útil para la consecución de los propósitos consignados en el programa fundacional de la orden religiosa; entre esos propósitos se encontraban la educación de los fieles, la acción evangelizadora en los asentamientos misionales de todo

8 Gerbi, 1955.

9 Furlong, 1994: 17-186.

10 Vargas Alquicira, 1989: 40-60. 
el mundo, la glorificación de las obras de Dios y la santificación de las almas a través del trabajo y del conocimiento ${ }^{11}$.

Así, los jesuitas llegaron al Nuevo Mundo con el fin de evangelizar y educar. Para culminar esa meta, entendieron que era conveniente comprender las sociedades nativas y el medio en que éstas se desenvolvían. A consecuencia de ello, y como prueba de su estancia y labor en los territorios recién descubiertos, dejaron un gran número de escritos sobre asuntos relacionados con el mundo natural y moral americano. Desde sus conventos y misiones, los soldados de Jesús redactaban los textos y los ponían a disposición de sus superiores a través de correos oficiales y conductos internos. El fundador de la congregación, San Ignacio de Loyola, ordenó en 1554 que se mantuviera una frecuente correspondencia entre los monjes y los priores, estructurando los asuntos que habían de abordar. Entre las cuestiones a tratar se encontraban las características físicas de la zona, el clima, la posición astronómica del territorio, las costumbres de los habitantes, etc. Esta práctica se vio reforzada a raíz de la Cédula Real de 1572, en la que se ordenaba que los centros eclesiásticos recogiesen noticias sobre aspectos geográficos, administrativos, naturales y educativos de los territorios de la Corona. En 1598, el prior Claudio Acquaviva dio instrucciones a todos los provinciales jesuitas para que redactaran textos historiográficos sobre sus misiones. Las crónicas debían incluir datos sobre la historia y la cultura de los pueblos y las particularidades de su naturaleza, pues de este modo los lectores podrían formarse una idea veraz de los retos de la labor misionera en el mundo ${ }^{12}$. La Cédula Real del 10 de junio de 1695, por otro lado, obligaba a los clérigos a permanecer en ultramar un mínimo de diez años antes de regresar a España; de manera que se prolongó el contacto entre ellos y los indígenas y se vio favorecido el intercambio de conocimientos entre unos y otros ${ }^{13}$.

Un lugar singular, en lo que se refiere a la investigación climatológica en la América española, ocuparon los cronistas religiosos de Indias. Sus trabajos estuvieron prioritariamente motivados por intereses evangelizadores, aunque también prestaron atención a asuntos administrativos, económicos, intelectua-

11 Harris, 1989: 29-65.

12 O’Malley, 1999: 3-37. Harris, 1999: 212-240. Meier, 2001: 423-441. Ledezma y Millones Figueroa, 2005: 9-26.

13 El interés de los jesuitas por el mundo natural y el intercambio de conocimientos con los nativos también fueron comunes en la América no española. Así, los misioneros jesuitas de la Nueva Francia intercambiaron con los nativos conocimientos médicos y terapéuticos. Esta vía de comunicación facilitó a los jesuitas el aprendizaje y la posterior catalogación de las propiedades curativas de diversas hierbas y raíces usadas por los indígenas con fines medicinales. Véase Greer, 2005: 135-146. 
les, etc. Estos personajes compararon frecuentemente el medio natural con el paraíso terrenal, en el cual situaron a los indígenas. De ahí que su insistencia en la armoniosa relación entre el hombre y el medio fuera adjetivada elogiosamente y tuviera como fin la gloria del Creador y la atracción de más novicios hacia la congregación ${ }^{14}$. El interés de los cronistas por los climas se debió a los influjos de naturaleza física y psíquica que dichos fenómenos ejercían en el ser humano ${ }^{15}$; los climas, además, formaban parte del hábitat natural del hombre y no eran sino obras divinas dignas de ensalzamiento ${ }^{16}$.

Especial mención merece la obra del padre José Acosta ${ }^{17}$, en la que apareció reflejada la interacción de los climas con las características geográfico-naturales de América y las cualidades morales de sus habitantes. Al mismo tiempo, el jesuita quiso acentuar la unidad indisociable entre el Viejo y el Nuevo Mundo; y aunque defendió que la naturaleza americana tenía peculiaridades distintivas, dejó claro que dichas peculiaridades participaban de la generalidad. Entre las cuestiones meteorológicas y climatológicas que abordó, cabría destacar las que se citan a continuación ${ }^{18}$. 1) Densidad del aire: disminución con la altura. 2) Radiación solar y temperatura del aire: diferencia entre el efecto directo de los rayos solares y el debido al del aire circundante. 3) Evaporación, condensación y precipitación acuosa: en la zona tórrida, la fuerza del Sol hacía que se elevasen los vapores oceánicos para deshacerse a continuación en forma de lluvias. 4) Vientos: clasificación según su dirección; adquirían las propiedades termo-hídricas de los lugares por donde pasaban; transportaban de un lugar a otro tanto los corpúsculos y emanaciones que flotaban en el aire como los fenómenos meteorológicos; comparación entre los vientos oceánicos y los del Mediterráneo; los vientos frescos eran la causa de que la zona tórrida fuese mucho más templada de lo que se creía.

El libro de Acosta ejerció una gran influencia durante varios siglos y fue traducido a varios idiomas. Desde el punto de vista historiográfico, proporcionó la pauta a seguir en la temática de las relaciones geográficas y las historias naturales y morales, pues se basaba en la continuidad existente entre

14 En la historiografía jesuítica, la descripción de la naturaleza desempeñó una función encomiástica, tanto en las áreas de influencia hispánica como en las de otras potencias europeas. Véase al respecto el citado trabajo de Greer, así como el de Carolino, 2005: 85-108.

15 La tradición hipocrática atribuía a los influjos del medio ambiente las cualidades físicas y mentales de los humanos. El entorno incluía el viento, el agua, el suelo, la vegetación, la orientación y localización de los asentamientos, las condiciones sanitarias, la dieta, el vestido, etc. Véase Glacken, 1967. Sargent, 1982. Urteaga, 1992.

16 Muñoz Pérez, 1982, vol. I: 135-188. Álvarez Peláez, 1991: 79-95. Glacken, 1967.

17 Acosta, 1590.

18 Blasco, 1987: 85-129. 
todos los elementos naturales y en la sustentación de lo moral en lo natural ${ }^{19}$. En esta misma línea cabría mencionar otras obras jesuíticas del siglo XVII ${ }^{20}$.

\section{Proyectos Jesuíticos de alcance ClimatolóGico. Siglo XVIII}

Durante el siglo XVIII, los jesuitas efectuaron múltiples exploraciones e incrementaron la producción de literatura apologética de la naturaleza. Algunos de ellos incorporaron modernos procedimientos de medida instrumental y mostraron una gran inclinación hacia el estudio de las ciencias naturales. Como en las centurias anteriores, las historias naturales y morales de estos clérigos tuvieron un carácter enciclopédico, y en ellas se representaban los seres como integrantes de un continuo vital con cada una de sus piezas en mutua interacción ${ }^{21}$. A través de estas obras, los jesuitas glorificaron la Creación, reivindicaron la exuberancia y la grandeza de la naturaleza americana y defendieron el carácter moral de los nativos; y gracias a ellas consolidaron su tradición erudita ${ }^{22}$.

Las crónicas e historias apologéticas de las misiones jesuíticas americanas sirvieron de reclamo para atraer nuevos misioneros y habitantes a las colonias. Cada reducción fronteriza podía ser para los monjes un punto de arranque hacia territorios desconocidos. Ayudados, defendidos y orientados en sus incursiones por los neófitos, éstos les amparaban de los peligros de la selva y les transportaban a lugares que pasarían a ensanchar las lindes de la civilización, de la cristiandad y de la Corona. Al cabo de un trienio, llegaban los procuradores de la metrópoli para visitar los colegios y los noviciados, donde ponderaban los trabajos realizados y los que quedaban por hacer ${ }^{23}$.

Desde la puesta en funcionamiento de sus propios circuitos de observación, acumulación y circulación de datos, la Compañía de Jesús fue creando una singular imagen del mundo. Las cartas enviadas por sus miembros a lugares remotos contribuían al intercambio organizado y sistemático de todo tipo de saberes. Este hecho fue contemporáneo de la expansión atlántica del mercantilismo y de las reformas borbónicas. De ahí que en las obras jesuíticas

19 Aguirre, 1957: 176-187. Pino, 2000: 295-326.

20 Torres, 1603. Acuña, 1641. Ovalle, 1646. Cobo, 1653.

${ }^{21}$ La historia natural aglutinó en su ámbito de estudio un amplio grupo de saberes y compartió contenidos y procedimientos de investigación con la meteorología, la medicina y la geografía; también se interesó por las relaciones entre el mundo natural y el moral. Véase Broc, 1971. Capel, 1995.

22 Ponce Leiva, 1992: 29-33. Furlong, 1994: 47-186. Millones Figueroa y Ledezma, 2005.

23 Furlong, 1994: 17-28. 
se mezclasen las noticias etnográficas, geográficas, climáticas, etc., con otras que se referían a la explotación de los recursos naturales, la agricultura, el comercio, las obras públicas y el urbanismo. La información transmitida -entre la cual se encontraba la climatológica- se administraba a través de células que tenían su base en los misioneros; seguía por los rectores y visitadores, que a su vez estaban comunicados entre sí y con los misioneros; después, continuaba en el provincial y concluía en el prior general asentado en Roma. Éste ponía a disposición de las demás células los documentos que elaboraban los provinciales. De modo que, en cualquier parte del mundo donde hubiese establecimientos jesuíticos, se tenía conocimiento de lo que sucedía en el resto. En este proceso, los clérigos cualificados ponían al servicio de la Compañía todo tipo de información útil y fiable que pudiese reportar conocimiento de la naturaleza y de los habitantes de los territorios. Esto, a su vez, facilitaba la organización efectiva de nuevos proyectos misionales $y$, en definitiva, hacía plausible la ampliación y consolidación de las áreas de influencia jesuítica tanto en los dominios hispánicos como en cualquier otra parte del globo ${ }^{24}$. Además, contribuía a la resolución de problemas prácticos. Piénsese, por ejemplo, que una oportuna comunicación climática podía favorecer la organización de viajes pastorales, la planificación de cultivos anuales o la elección de lugares aptos para el establecimiento de asentamientos humanos ${ }^{25}$.

Del análisis de las fuentes consultadas, se desprende que es posible dividir la actividad climatológica de los jesuitas en tres grandes apartados: 1) la practicada por los misioneros -en su mayor parte, procedentes de la metrópoli- que permanecieron durante períodos relativamente largos en Iberoamérica; 2) la de los clérigos de mayoría criolla, abocados a raíz de su extrañamiento a publicar los conocimientos adquiridos en el exilio; 3) la de las elites intelectuales de la metrópoli, que conocían las realidades naturales y morales del Nuevo Mundo aunque nunca hubiesen estado en él.

En su afán por comprender el mundo natural y moral de los nuevos territorios, los misioneros ${ }^{26}$ realizaron trabajos de campo y basaron sus investiga-

24 Harris, 1996: 287-318. Harris, 1999: 212-240.

25 Se podrían añadir otras aplicaciones prácticas, como la promoción de proyectos educativos y legislativos, la participación en campañas sanitarias, la navegación, etc. En suma, los efectos del clima en las sociedades, así como en la salud y el carácter moral de los habitantes, encajaban dentro del marco de las concepciones ambientalistas de la naturaleza y contemplaba el papel del hombre como agente modificador de la naturaleza. Véanse en la nota 2 los trabajos que se pueden consultar al respecto.

26 Rojas, 1707. Maroni, 1738. Gumilla, 1745. Quiroga, 1753. Guevara, 1764. Falkner, 1760; 1774. Barco, 1767. Sánchez Labrador, 1769; 1771-1776. Camaño Bazán, 1778. Juárez, 1789. Gili, 1789. Alegre, 1842. 
ciones en lecturas y observaciones propias y ajenas. No extraña encontrar en sus obras todo un plan de trabajo relacionado tanto con los diferentes campos del saber que el espacio americano les ofrecía como con las actividades que desempeñaron en aquel escenario. Dicho plan guardó coherencia y continuidad durante siglos; y sobrepasó los objetivos prioritarios de la Compañía de narrar la conquista espiritual del Nuevo Mundo y agregar nuevos adeptos y colonos a los territorios ${ }^{27}$.

Entre los intereses de carácter científico más sobresalientes de los misioneros, figuraban las descripciones y las causas de los climas locales y regionales iberoamericanos, las relaciones de dichos fenómenos naturales con el medio y el hombre y las comparaciones climáticas. En el marco de sus labores apostólicas, estos religiosos exaltaron vivamente la naturaleza americana, y sus escritos presentaron una marcada apología de ésta, de los habitantes del Nuevo Mundo y de la Creación divina ${ }^{28}$; de ahí que algunos de ellos intervinieran en las polémicas sobre la supuesta inferioridad de la naturaleza americana ${ }^{29}$. Además, los misioneros formaron parte de los eslabones más básicos de las cadenas informativas implicadas en la investigación de las realidades geográficas, naturales y morales de las Indias. No sólo exploraron territorios y observaron directamente la naturaleza, sino que consultaron innumerables documentos de quienes les precedieron y solicitaron datos a nativos e interlocutores. Para agilizar y garantizar el intercambio de información, los misioneros mantuvieron asidua correspondencia con sus hermanos de congregación $\mathrm{y}$ tuvieron un trato frecuente con las autoridades - civiles y religiosas- y con personajes relevantes del panorama cultural. En el transcurso de sus actividades indagadoras, hicieron las veces de recopiladores, analizadores y difusores de noticias. Y como fruto de sus pesquisas, redactaron obras de amplios contenidos, entre los que se encontraban los climatológicos. El asiento donde efectuaron sus reflexiones se encontraba en las propias sedes misionales; y fueron estos mismos lugares los escogidos para ordenar y sintetizar las noticias recabadas y componer sus escritos. Las actuaciones de estos clérigos se prolongaron a lo largo de toda o gran parte de su estancia en los territorios

27 Torales Pacheco, 2005: 195-224.

28 El saber científico ilustrado se desenvolvió dentro de un ámbito sincrético de concepciones creacionistas, teleológicas, ambientalistas y fijistas de la naturaleza. Las evidencias experimentales surgidas a raíz del ensanche del conocimiento geográfico y natural, así como las novedades introducidas en el quehacer científico, servían muchas veces para confirmar la idea de plenitud divina y de un plan creador. Véase Shapin, 2000.

29 Este asunto se tratará seguidamente con cierto detalle, al hablar de los jesuitas criollos. 
ultramarinos; y si alguna vez se vieron interrumpidas, sólo fue por motivo de muerte o expulsión ${ }^{30}$.

Tras el extrañamiento de la Compañía de Jesús, los clérigos criollos ${ }^{31}$, imbuidos de fuertes sentimientos patrióticos y aventajados por el recuerdo de la experiencia directa adquirida durante muchos años, emprendieron un proyecto historiográfico y elogioso de los territorios de origen. Con tal propósito, y exentos de las obligaciones pastorales y educativas que otrora les impusiera la congregación, recordaron sus observaciones de la naturaleza y sus contactos con los pobladores. Tuvieron que valerse para ello del intercambio de información por vía oral y epistolar, lo mismo que de las lecturas de obras contemporáneas y pretéritas pertenecientes a reconocidos autores del ámbito científico. Conocedores de numerosos ejemplos empíricos, los jesuitas criollos se esforzaron aún más que sus hermanos misioneros en desmentir las acusaciones despectivas vertidas en las obras de algunos autores europeos ${ }^{32}$ hacia la naturaleza americana y sus habitantes. Hechos, evidencias y observaciones, además de la permanente alusión a la diversidad natural y climática de América, fueron las armas que emplearon para combatir ese menosprecio ${ }^{33}$. Motivados, en fin, por la nostalgia, echaron de menos las tierras y los habitantes que dejaron atrás y se consolaron con la rememoración de los papeles confiscados por las autoridades españolas. Esto les animó a recomponer sus escritos y a referirse constantemente a los de sus predecesores. De esta forma, mostraron su identidad singular al mundo y dieron a conocer las maravillas natu-

30 Furlong, 1984: 193-202. Vargas Alquicira, 1989: 40-60. Harris, 1996: 287-318; 1999: 212-240.

31 Clavijero, 1757; 1780. Molina, 1776-1787. Velasco, 1789. Gómez de Vidaurre y Girón, 1789. Iturri, 1798.

32 Leclerc (conde de Buffon), 1749. Pauw, 1768. Raynal, 1775. Robertson, 1777.

33 Para Buffon, el lugar geográfico y los seres vivos que lo poblaban diferían unos de otros a causa de las influencias ambientales, particularmente, las climáticas. Esto, a su juicio, también era aplicable a la especie humana. El aristócrata francés consideró que en los climas templados se encontraban los hombres más civilizados y mejor proporcionados de la Tierra, es decir, los europeos de las latitudes medias. Sin embargo, su teoría chocaba con una evidencia innegable: el continente americano, extendido de Norte a Sur, presentaba todo tipo de climas y su población originaria era relativamente homogénea. Buffon resolvió esta aporía mediante el argumento de que tanto el clima como los nativos americanos eran más uniformes que los del viejo continente. Esta visión cautivó la imaginación y el espíritu polémico de autores como Pauw, Raynal y Robertson, quienes, igual que Buffon, no estuvieron jamás en América; de modo que trataron de establecer generalidades a partir de relaciones y analogías entre unos fenómenos particulares que no observaron personalmente. Sobre estos asuntos, véase: Gerbi, 1955: 139-145. Vargas Alquicira, 1989: 40-60. Torales Pacheco, 2005: 195-224. Huffine, 2005: 279-302. 
rales de América. No obstante, sus libros tardaron varios años en salir a la luz y sus primeras tiradas editoriales fueron escasas ${ }^{34}$.

Por último, los integrantes de la clase intelectual jesuítica ${ }^{35}$ permanecieron en Europa, centro de la influencia cultural y política dentro y fuera de la orden. Gracias a su tarea organizada de recopilación de documentos, análisis de datos y comparación de unos y otros con la tradición clásica, lograron hacer un balance de todo el conocimiento adquirido y completaron un cuerpo de obras geográficas, históricas y naturalistas de las Indias Occidentales. En sus escritos ordenaron, explicaron y narraron todas las novedades concernientes a los territorios en cuestión ${ }^{36}$. Estas labores se realizaron en los principales centros de saber administrados por la orden o bajo fuerte influencia de sus miembros. Los fines podían ser varios: la educación de las elites intelectuales locales; la reflexión sobre las características geográficas, morales y naturales del Nuevo Mundo; el deseo de alabar las creaciones de Dios sobre la Tierra; y la participación en proyectos gubernamentales de síntesis y redacción de obras de conjunto ${ }^{37}$. Andrés Burriel, particularmente, concedió credibilidad a los últimos y más recientes datos que habían llegado a su conocimiento sobre las características geográficas de California y los plasmó en su obra ${ }^{38}$. Además, abordó el problema de si California era una isla o una península, actuó con rigor al incluir mapas fiables y noticias fidedignas en su obra y expresó su deseo de corregir los errores y falsedades de los geógrafos ingleses y franceses ${ }^{39}$. Miguel Venegas, por su parte, aprovechó la correspondencia, las relaciones históricas y los mapas elaborados entre finales del siglo XVII y principios del XVIII por los padres Juan María de Salvatierra, Eusebio Kino, Fernando Konskak, Juan de Ugarte, Sebastián de Sistiaga, Segismundo Taraval y otros para escribir su crónica de California ${ }^{40}$.

34 Furlong, 1984: 193-202.

35 Burriel, 1757. Venegas, 1757.

36 Desde el primer viaje de Colón, las novedades referidas suponían un reto para los estudiosos de la época, por lo que era lógico que la clase intelectual jesuítica, tan influyente en el mapa científico europeo, reflexionara sobre la naturaleza americana. Véase Feldhay, 1999.

37 Millones Figueroa, 2005: 27-47.

38 Burriel, 1757.

39 Hermosilla, 1908: 413-415.

40 Torales Pacheco, 2005: 195-224. 


\section{CONTENIDO CLIMATOLÓGICO Y PROCEDIMIENTOS DE INVESTIGACIÓN}

Los jesuitas se distribuyeron por todos los virreinatos, interesándose por la naturaleza y las características geográficas de los territorios. Dedicaron gran parte de su tiempo al estudio de los climas locales y regionales e insertaron en sus obras los resultados obtenidos. Los géneros literarios que más practicaron fueron las relaciones históricas y las historias naturales y morales. Para producirlos, se basaron tanto en sus observaciones personales directas -algunas de ellas, instrumentales- como en la consulta de fuentes ajenas y en el seguimiento de modelos narrativo-cognoscitivos de fuerte raigambre en la congregación ${ }^{41}$. Redactaron la mayor parte de sus escritos en castellano, vehículo lingüístico de uso común en la vida cultural y administrativa del mundo hispánico desde el Renacimiento. Dicha lengua, además, se mostró flexible en la incorporación de términos referentes a las realidades naturales americanas y a las novedades de la ciencia moderna; y era apta para comunicar el saber climatológico a un público interesado que, en general, desconocía el latín. Como cabía esperar, los textos en italiano se editaron durante el exilio jesuítico en la península itálica.

Los misioneros jesuitas clasificaron los climas desde diferentes puntos de vista. Así, influenciados muchos de ellos por la tradición hipocrática, distinguieron entre climas benignos y perjudiciales para la salud humana. En virtud de esa misma concepción y de las corrientes que encontraban en el entorno natural una de la causas de la diversidad cultural del género humano, vincularon el clima a la sociedad, al carácter moral de los habitantes y a la fertilidad de la tierra. También contemplaron el clima como un factor determinante de la adaptabilidad de los seres vivos al medio ${ }^{42}$. En el ámbito de la tradición geográfica, los misioneros clasificaron los climas según la latitud del territorio; pero, además de guiarse por este criterio, tuvieron en cuenta la interacción entre el clima y ciertos accidentes geográficos y fenómenos naturales, como la altura del terreno, la acción de los vientos, la humedad y la proximidad de cumbres montañosas y aguas superficiales ${ }^{43}$.

41 Particularmente, el de Acosta.

42 Durante el siglo XVIII persistió la idea de la influencia del ambiente en la salud y en la naturaleza moral, social, psicológica y cultural de los individuos. Debía mucho al saber farmacéutico, a la medicina y a la observación del tiempo atmosférico. Las combinaciones de la cuaterna [frío, caluroso, seco, húmedo] producían efectos diferentes en los organismos y condicionaban lo salubre o insano del clima. Véase Sargent, 1982. Iglesias, 1984: 202-217. Urteaga, 1992. Capel, 1998-1999.

43 Los más venerables representantes de esta concepción fueron los geógrafos griegos Hiparco, Estrabón, Eudoxo, etc., cuyas propuestas persistieron en lo esencial hasta la Ilustra- 
Los asuntos climatológicos tratados en las obras de los misioneros fueron amplios y variados. Así, fue frecuente el interés por las estaciones y los meteoros típicos de cada región y época del año. En relación con la salubridad de los climas y la pureza del aire, los misioneros estudiaron las exhalaciones terrestres y las variaciones del tiempo atmosférico que condicionaban el hábitat y las actividades sociales y económicas de los seres humanos ${ }^{44}$. Estos autores se fijaron especialmente en los fenómenos climáticos insólitos; pues, dados sus fines apologéticos, se vieron impulsados a rodear de un aura de veracidad lo extraño y fabuloso ${ }^{45}$. Como se vio en el epígrafe anterior, los argumentos en favor de la singularidad de las tierras y de los climas perseguían un refuerzo de los lazos afectivos con los habitantes, la atracción de novicios a las misiones y el ensalzamiento de la tarea evangelizadora y cultural de la Compañía de Jesús. Pero, además, los clérigos quisieron reivindicar las virtudes de lo que consideraban su tierra de adopción; y el significado profundo de este afecto, que sólo con suficiente perspectiva histórica se alcanzaría a vislumbrar, muy bien pudo ser el de instaurar una identidad patria ${ }^{46}$. Por otro lado, la información climatológica proporcionada por los misioneros tuvo un carácter descriptivo y abarcó un ámbito geográfico muy extenso. La tendencia general fue proporcionar explicaciones causales de los fenómenos climáticos e integrar la información referida en estudios amplios sobre el medio terrestre, la sociedad y el ser humano ${ }^{47}$. Compruébese lo expuesto anteriormente con los casos particulares que a continuación se relatan.

Al padre Pablo Maroni le interesaron las condiciones naturales que reunían los hábitats de los indios, las inclemencias del tiempo que estos tenían que soportar y la relación entre el calor y la humedad. De ahí se derivó una distinción entre los climas de las regiones bajas y los de las más elevadas. En

ción. Estos personajes identificaron los climas con bandas latitudinales paralelas al ecuador terrestre, si bien dichos límites no respondían a ninguna realidad física. En el siglo XVIII, la diferenciación en zonas templada, tórrida y fría del planeta aún aludía a los grados de inclinación de los rayos solares, pero también a las características térmicas y biogeográficas de regiones o lugares. Al conjunto de las peculiaridades que caracterizaban los climas locales o regionales se le dio el nombre de «temperamento». Véase Glacken, 1967. Urteaga, 1992.

${ }^{44} \mathrm{La}$ atmósfera estaría constituida por vapores y exhalaciones terrestres de diferente densidad que se superponían en diferentes estratos. Dichos vapores y exhalaciones podían contener las substancias causantes de las enfermedades y eran susceptibles de trasladarse de un lugar a otro a causa de los vientos. Además, la revitalización del pensamiento hipocrático en el siglo XVIII derivó en un afianzamiento de las ideas sobre los factores que condicionaban el reparto geográfico de las enfermedades. Véase Sargent, 1982. Urteaga, 1992.

45 Ledezma y Millones Figueroa, 2005: 9-26.

46 Vargas Alquicira, 1989: 40-60. Torales Pacheco, 2005: 195-224.

47 Concretamente, en obras de contenido geográfico y de historia natural y moral. 
relación con lo cual, Maroni señaló que el temple de la región bañada por el río Marañón era húmedo y bastante caluroso, circunstancia que relacionó con la aparición de una gran variedad de sabandijas y la putrefacción de los alimentos ${ }^{48}$. Maroni también se ocupó de los climas locales de diversos enclaves y los comparó entre sí.

$\mathrm{Su}$ hermano de congregación, José Gumilla, fue un observador atento y curioso que mostró un mundo físico nuevo y desconocido. El clérigo valenciano hizo frecuentes alabanzas de los climas americanos, los comparó con los de diversos lugares de España y se interesó por la relación entre el clima y el carácter moral de la población autóctona. Además, recurrió al argumento del Designio para explicar la diversidad climática de los territorios adyacentes al río Orinoco; de modo que, a su juicio, Dios creó dichos territorios con la finalidad de que fuesen habitables ${ }^{49}$. Por otra parte, Gumilla veía en la redondez de la Tierra y su disposición con respecto al Sol la principal causa de la diversidad climática de la zona tropical ${ }^{50}$. Pero también señaló algunas causas ambientales, como la altura de las cumbres y la existencia de nieves permanentes en ellas; así, a mayor distancia de las montañas, con menos fuerza llegaban los vientos fríos y, por tanto, mayor era el calor. De ahí la división en tierras frías, templadas y calientes; en cada una de esas regiones se daban condiciones de vida particulares y exclusivas, a modo de indicadores del clima característico. Los procedimientos empleados por Gumilla para apreciar la intensidad del frío y del calor se basaban en la sensación directa y en la observación de los efectos de esos fenómenos sobre el cuerpo humano ${ }^{51}$. Y continuamente se refirió a la obra de Acosta.

48 Maroni, 1738: 140.

49 En la cultura occidental, el Designo iba unido a la idea de tierra creada por Dios. Y también estaba relacionado con el finalismo y el antropocentrismo, pues el Designo no podía ser otro que el de la Tierra creada para el hombre y, en general, para la vida. Véase Glacken, 1967.

50 Gumilla, 1745: 72.

51 A falta de instrumentos de medida, ese era un modo bastante usual de operar. Los instrumentos meteorológicos estuvieron disponibles desde finales del siglo XVII. Su uso se extendió en el siglo XVIII, especialmente en el último tercio, con el fin de obtener largas series de datos que llevaran a encontrar regularidades atmosféricas y climáticas. Véase Middleton, 1969. Feldman, 1983: 193-286. Jankovic, 2000. Lüdecke, 2005: 123-131.

En el mundo hispánico, sin embargo, no fue tan común su empleo; a excepción de los registros termométricos auspiciados por la Real Academia Médico Matritense en 1737, no hay pruebas de que se efectuaran mediciones con aparatos meteorológicos hasta el año 1777 , después de la supresión de la Compañía de Jesús. Véase García Hourcade, 2002: 100-132. Guijarro Mora, 2005: 159-190. Valverde Pérez, 2007: 55-132. Guijarro Mora y González de la Lastra, 2010: 179-228. 
En el virreinato del Río de la Plata, el padre José Quiroga ${ }^{52}$ escribió sobre los climas regionales y locales y los relacionó con la salud de los habitantes y los frutos de la tierra. Así, sobre el temperamento de Cubayá dijo que era ardiente y húmedo $\mathrm{y}$, por tanto, insano; la causa de ello se encontraba en las copiosas lluvias, y la consecuencia inmediata era la abundancia de mosquitos $^{53}$. A José Guevara, por su lado, le interesaron las condiciones que reunía Paraguay para levantar ciudades, y realzó la riqueza natural del país y las cualidades estéticas de su paisaje ${ }^{54}$. La rica vegetación de las praderas y la variedad de sus vistosas flores eran, en su opinión, una marca inconfundible de la abundancia de bienes naturales que Dios había regalado a sus habitantes ${ }^{55}$. En cuanto al inglés Thomas Falkner, éste disertó en su relato acerca de las regiones patagónicas, observando el extremo frío de la región, las nieves perpetuas, la vegetación y los frutos que le eran propios ${ }^{56}$. Antes, el propio Falkner alabó el clima de las islas Malvinas y comparó el ambiente natural con el paraíso terrenal ${ }^{57}$. Algo similar hizo el padre Silvestre Antonio de Rojas, quien atribuyó la longevidad de los habitantes de la región de los Césares a lo benigno del clima ${ }^{58}$.

El toledano José Sánchez Labrador estudió los climas paraguayos, basándose en su propia experiencia y en una gran cantidad de observaciones de carácter cualitativo. Dedicó una parte de su obra a la descripción de los fenómenos meteorológicos y climatológicos característicos de la región donde ejerció. También dio explicaciones acerca de la relación entre las enfermedades ordinarias y el clima. Una de sus contribuciones más originales al conocimiento de este fenómeno fue la de atribuir el carácter perenne de la flora rioplatense a una cierta estacionalidad climática. Para el jesuita, el clima estaba determinado tanto por la forma y posición de la Tierra respecto al Sol como por la influencia de otros factores geográficos y naturales ${ }^{59}$; en este sentido, encontró que tan sólo las lluvias y los vientos del sur, oriente y po-

52 José Cardiel y José Quiroga formaron parte de una expedición organizada por la Marina para explorar el estrecho de Magallanes. El propósito principal era señalar algunos puntos favorables en los que establecer asentamientos de pobladores.

53 Quiroga, 1753: 367-368.

54 Igual que otros jesuitas establecidos en Paraguay, y como hicieran muchos participantes en expediciones científicas (Charles de La Condamine, Antonio de Ulloa, Félix de Azara, etc.), Guevara describió en su obra una naturaleza paradisíaca. Véase Huffine, 2005: 279-302.

55 Guevara, 1764, citado en Angelis, 1910, vol. II: 59.

56 Falkner, 1774, citado en Angelis, 1910, vol. I: 314.

57 Falkner, 1760, citado en Angelis, 1910, vol. I: 371.

58 Rojas, 1707, citado en Angelis, 1910: 358.

59 Sánchez Labrador, 1769, edición de 1910: 145-146. 
niente ayudaban a refrescar algo la atmósfera paraguaya; esas lluvias, por lo demás, eran abundantes y copiosas en los meses de verano. En cuanto a los vientos, el del sur era frío y nocivo para la salud; el viento del norte, por el contrario, aunque era cálido, no causaba daño al cuerpo humano; los del este y el oeste, en fin, eran moderados, debido a la posición de las tierras y de las aguas que sobrevolaban. Por otra parte, las furiosas tempestades veraniegas siempre aparecían en el horizonte combinadas con nubes densas e intensos truenos, desatándose finalmente con grandes rayos y copiosas lluvias que refrigeraban y fecundaban la tierra ${ }^{60}$.

El mismo autor realizó numerosas observaciones del medio natural y estableció relaciones entre éste y los fenómenos climáticos ${ }^{61}$. Igual que Guevara, Falkner y Rojas, empleó términos elogiosos para referirse al clima paraguayo; y fundamentó sus observaciones en las impresiones visuales directas, las sensaciones y los efectos de los fenómenos físicos en los organismos ${ }^{62}$. Por último, recurrió a algunos resultados obtenidos por relevantes personajes del panorama científico contemporáneo (Boerhaave, Mersenne, S'Gravesande, Réaumur, Franklin y otros) para explicar diversos aspectos específicos de los meteoros ${ }^{63} \mathrm{y}$ de las características climáticas de Paraguay ${ }^{64}$.

Pocas diferencias se pueden apreciar entre las obras de los misioneros jesuitas establecidos en las márgenes del Amazonas y el Orinoco y las de quienes escribieron sobre los climas rioplatenses. Como se ha podido comprobar, en ambas situaciones hubo una adaptación bastante fiel al esquema que a finales del siglo XVI estableciera el padre Acosta. Es decir, unos y otros integraron los asuntos naturales y morales en un mismo orden de cosas. No conformes con describir los climas -a base de observaciones sensoriales cualitativas y de consultas de fuentes ajenas-, se emplearon a fondo en la explicación de las causas de la diversidad climática americana; en referencia a esto, determinaron que tales causas se hallaban en la posición astronómica del territorio y en algunos condicionamientos geográfico-ambientales. Además de abordar los asuntos anteriores, los clérigos se interesaron por la estacionalidad y la periodicidad climática, así como por los signos vitales y socioculturales indicadores de los diversos climas. Para referirse a estos fenómenos naturales, emplearon términos comunes del castellano que denotaban cierta personifica-

\footnotetext{
60 Ibidem: 148.

61 Sainz Ollero et al., 1989: 106-129 y 204-209.

62 Sánchez Labrador, 1769: 146-148.

63 Sobre los mecanismos de formación de los fenómenos meteorológicos acuosos, que los autores referidos y muchos otros estudiaron, véase Middleton, 1965.

${ }^{64}$ Sánchez Labrador, 1771-1776, citado en Furlong, 1948: 140-143.
} 
ción: temple, temperamento, [clima] benigno, [calor] molesto, sentir [los efectos del clima], [causar] fatiga, [temperamento] sano, [clima] insalubre, sudar [a causa del calor], regularidad [climática o estacional], [encontrar] refrigerio, [terreno] infeliz, etc.

A veces, las noticias sobre los climas eran dispersas y escasas, limitándose sus autores a escribir -con mayor o menor profusión de datos- sobre el temple, la fertilidad de la tierra, las precipitaciones y las consecuencias de ello para la agricultura, la ganadería y la medicina. En todo caso, los autores referidos se ciñeron a una línea narrativa y cognoscitiva muy parecida a la de los mencionados en los párrafos anteriores. Así, Miguel del Barco disertó sobre el clima caluroso de California y la escasez de lluvias, lo que hacía que el territorio, en general, fuese poco apto para la agricultura ${ }^{65}$. Mientras, Francisco Xavier Alegre resaltaba la fertilidad del suelo novohispano frente a la esterilidad del terreno de la Florida; y atribuía dicha fertilidad a lo templado del clima y a las numerosas vertientes que facilitaban la formación de aguas superficiales $^{66}$. En otras circunstancias, los misioneros fueron pródigos en explicaciones causales sobre cuestiones de geografía e historia natural ${ }^{67}$.

Los jesuitas desterrados coincidieron en presentar a sus lectores las características climáticas de América desde el punto de vista de sus propias experiencias personales y de los autores que, como ellos, habían observado directamente los climas americanos ${ }^{68}$. Por eso, rechazaron las ideas de aquellos filósofos europeos que, sin haber estado jamás en el nuevo continente, fundamentaron sus ataques contra la naturaleza americana partiendo de la premisa de que ésta era inferior a la europea y dando ejemplos contrarios a la experiencia.

Así, una de las contribuciones más interesantes al saber climatológico efectuadas por Francisco Xavier Clavijero, Juan Ignacio Molina, Juan de Velasco, Félix Gómez de Vidaurre ${ }^{69}$ y Francisco Iturri fue que las leyes naturales eran las mismas en el Viejo y en el Nuevo Mundo y, por lo tanto, que las diferencias climáticas entre uno y otro obedecían a idénticas causas físicas.

65 Barco, 1767: 3-6.

66 Alegre, 1842: 38.

67 Camaño Bazán, 1778. Juárez, 1789. Gili, 1789.

68 El conocimiento resultante de la experiencia fue muy apreciado por los jesuitas. Si algo era contrario a la experiencia, entonces quedaba deslegitimado por inefectivo, no fiable e inútil. Véase Harris, 1989: 29-65.

69 Sobre la intervención de Clavijero, Molina y Velasco en la polémica en torno a la naturaleza americana y el contenido de sus historias naturales, véase Navia Méndez-Bonito, 2005: 225-250. Acerca del mismo asunto en el caso de Vidaurre, véase Casanueva, 2001: 207-235. 
Según estos autores, el hecho de que en América se diera una mayor diversidad climática que en Europa se debía a tres motivos. Ante todo, a la disposición del territorio con respecto a los rayos del Sol; después, a la estructura y relieve del terreno y a la influencia de la vegetación y de las aguas superficiales; finalmente, a los regímenes de vientos en cada zona. El clima en América, en suma, era un ente natural tan fijo y cíclico como en Europa; y tan inalterable como lo era el entorno natural, sólo que presentaba ciertos rasgos distintivos y circunstancialmente anómalos y cambiantes ${ }^{70}$. Por lo demás, los esquemas narrativos, explicativos y cognoscitivos de los cinco clérigos mencionados obedecían básicamente al modelo del padre José Acosta; la obra de Juan Ignacio Molina, en particular, presentó la novedad de que incorporó algún dato termométrico. Véase esto a continuación con más detalles.

A Francisco Xavier Clavijero le interesó la historia natural, la etnografía y la cultura de los indios, así como el aprovechamiento de los productos naturales de California. El mexicano condicionó el clima de dicho territorio a la estructura y a la calidad del terreno, y lo relacionó con las producciones vegetales, las enfermedades de los habitantes y los fenómenos atmosféricos violentos:

El aspecto de la California es, generalmente hablando, desagradable y horrido, y su terreno quebrado, árido, sobre manera pedregoso y arenoso, falto de aguas y cubierto de plantas espinosas donde es capaz de producir vegetales, y donde no, de inmensos montes de piedras y arena. El aire es caliente y seco, y en los mares perniciosos a los navegantes, pues cuando se sube a cierta latitud, ocasiona un escorbuto mortal. Los torbellinos que a veces se forman son tan furiosos, que desarraigan los árboles y arrebatan consigo las cabañas. Las lluvias son tan raras, que si en el año caen dos o tres aguaceros, se tienen por felices los californios. Los rocíos, si fueran abundantes, pudieran, como en el Perú, suplir en la California la falta de lluvias; pero también son escasísimos ${ }^{71}$.

El mismo autor reservó una parte de su libro fechado en 1780 al estudio de la naturaleza. La estructura y el contenido de la obra seguían la división y el orden clásico de otros textos similares. Comenzaba por la descripción física y geográfica de México, sus límites y su clima, para dedicarse luego a los minerales, los vegetales, los animales y el hombre. Sobre el clima, dijo el clérigo que había de varias clases: unos sanos y otros insanos, y las causas

70 En el último tercio del siglo XVIII, los seguidores del ambientalismo hipocrático y los cultivadores de la meteorología negaban el cambio climático. Sobre las propuestas ilustradas acerca del carácter fijo o cambiante del clima, véase Feldman, 1993: 23-40.

71 Clavijero, 1757: 11-12. 
de unos y otros eran naturales. Así, la benignidad del clima se debería a la pequeña variación térmica que se daba entre las diferentes estaciones anuales ${ }^{72}$; y las causas de lo último, a su vez, serían la pureza de la atmósfera, la poca oblicuidad de los rayos solares y la prolongada estancia del Sol sobre el horizonte. En los territorios distantes de la línea equinoccial, por el contrario, las nubes oscurecían la claridad del firmamento y las nieves sepultaban las producciones de la tierra. Los motivos que templaban el ardor del estío mexicano eran las copiosas lluvias de abril a octubre, las nieves perpetuas, los vientos frescos y la brevedad del curso del Sol sobre el horizonte. A falta de instrumentos con los que tomar medidas, Clavijero ofreció una idea de las características térmicas e hídricas de la zona a base de observaciones basadas en las sensaciones corporales, la escasez de hielos y nubes y la virulencia de algunos fenómenos meteorológicos ${ }^{73}$.

Juan Ignacio Molina, por otro lado, mantuvo que el clima de Chile era benigno, templado y óptimo para la vida. Por esta razón, había un variadísimo número de animales que se adaptaban muy bien al medio ambiente y las plantas crecían en un suelo fértil y rico en minerales; además, las especies animales y vegetales trasladadas desde Europa se aclimataban sin dificultad. La imagen proyectada era apacible, como de una continua primavera, con un radiante cielo azul y una extraordinaria fertilidad de la tierra. El chileno determinó las estaciones del año y recalcó su contraposición con las de Europa. Y clasificó minuciosamente los principales fenómenos meteorológicos (ácueos, aéreos e ígneos) de Chile, señalando su distribución espacial y temporal. También profundizó en las causas de dichos fenómenos, obtuvo algunas regularidades sobre su formación e interacción mutua y contempló la posibilidad de predecirlos. Además de realizar comparaciones entre los climas chilenos y los de otros países próximos ${ }^{74}$, proporcionó un escueto dato cuantitativo de la temperatura:

A la regular alternativa de todos estos vientos periódicos debe aquel Reyno el agradable temperamento que disfruta continuamente en las estaciones cálidas; y que, al parecer, no se podía esperar en una situación tan próxima á la Zona Tórrida, porque con efecto se verifica, concurriendo para más refrescar el ayre las mareas continuas, las rociadas nocturnas, y cierta aura suave que desciende de los montes nevados de la cordillera; y que en nada tiene que ver con los montes orien-

72 Para la medicina ambientalista de la época, las modificaciones bruscas de la temperatura alteraban el equilibrio orgánico y propiciaban la aparición de enfermedades. Véase Sargent, 1982.

73 Clavijero, 1780: 50-52.

74 Molina, 1776-1787: 15-25. 
tales. A favor de unos refrigerios tan agradables, es tal la benignidad del calor excesivo, que jamás provoca á sudar estando á la sombra: de modo que los habitantes de la parte marítima se visten del propio modo en invierno que en verano. En los valles mediterráneos, donde siempre es mayor el calor, suele subir el mercurio en el termómetro de Réaumur á los 25 grados, y son deliciosísimas en el país las noches estivas; sin embargo de los cual, concurriendo este calor agradable con el subterráneo, que allí aparece más activo que en ninguna otra parte, basta para dar perfecta madurez á todos los frutos, sin exceptuar los que acuden únicamente entre los Trópicos... ${ }^{75}$.

Mientras, Juan de Velasco relacionó el clima de Quito con la configuración del terreno, la forma y posición de la Tierra respecto al Sol y algunos condicionantes naturales, como la altura del terreno, la insolación, las nieves perpetuas, los vientos y la humedad. Desde su exilio italiano, el quiteño comparó las causas del clima de su país con las de los climas europeos, y las relacionó con la salud y las producciones vegetales ${ }^{76}$. Igual que Clavijero y Molina, Velasco contendió contra Buffon y sus seguidores ${ }^{77}$.

Por su parte, Félix Gómez de Vidaurre y Girón consideró que Chile era un paraíso natural abundante en especies animales y vegetales en el que se podía disfrutar de una atmósfera diáfana ${ }^{78}$. Le pareció que el clima de Chile era constantemente benigno, pues no padecía rigores extremos y estaba asociado a una riqueza natural sin parangón en el resto del globo ${ }^{79}$.

El español Francisco Iturri, por último, negó que la naturaleza americana estuviera exhausta y desustanciada, como aseguraban sus detractores. Tras señalar los errores en los que estos incurrieron, les reprochó que no hubiesen leído las crónicas que, desde el siglo XVI, facilitaban datos verídicos acerca de la naturaleza americana. De hecho, recordó que muchos exploradores se creyeron en el paraíso terrenal cuando observaron la rica variedad natural de América y la bondad de los climas. Sus referencias a medidas instrumentales fueron escasas y se centraron en la recomendación de emplear el barómetro para medir la altura de las montañas ${ }^{80}$. En fin, Iturri defendió que los principios que regían los fenómenos naturales en Europa y en América eran idén-

\footnotetext{
75 Ibidem: 26.

76 Velasco, 1789: 54-56.

77 Ibidem: 57.

78 Gómez de Vidaurre y Girón, 1789, vol. I: 20.

79 Ibidem: 42.
}

${ }^{80}$ Los seguidores de Buffon presentaban como prueba de la insalubridad de los climas americanos el hecho de que hiciese frío en las alturas pequeñas. Iturri argumentó que si hubieran tomado medidas barométricas con respecto al nivel del mar, se habrían dado cuenta de la verdadera elevación de las montañas. Véase Iturri, 1798: 63. 
ticos. De ahí, por ejemplo, que el frío produjese los mismos efectos en las montañas de la zona tórrida que en las cumbres de la cordillera andina o de la pirenaica ${ }^{81}$.

Como representante de las elites jesuíticas que permanecieron en Europa, Andrés Marcos Burriel concedió credibilidad a los más recientes datos que habían llegado a su conocimiento sobre las características geográficas de California. Respecto al clima, arguyó que, dada la gran extensión del país, debería ser bastante variado. De forma particular, relacionó el temple seco y cálido de algunas zonas con la aspereza y esterilidad de la tierra. Y, como otros hermanos de su congregación, estableció algunas clasificaciones climáticas, señaló los beneficios económicos que se podían extraer de los recursos naturales y reflexionó sobre la idoneidad de establecer asentamientos y misiones en determinados lugares ${ }^{82}$.

\section{Conclusiones}

El saber climatológico de los jesuitas asentados en la América española tuvo una orientación marcadamente empírica y utilitaria. La explicación y la legitimación de dicho saber se encontraban en los valores espirituales del ideario religioso de San Ignacio de Loyola y en los fines misionales y educativos perseguidos por éste. Y su puesta en práctica fue posible gracias a la propia estructura jerárquica y corporativa de la congregación, la cual demostró ser capaz de formar y desplegar por todo el mundo agentes que proporcionasen información fiable a sus superiores y que mantuviesen contactos regulares con las elites intelectuales europeas. Por otro lado, el contexto científico que presidió el saber en cuestión fue el ambientalismo, corriente que se ocupaba de los estudios amplios y generales del territorio y de la población y cuyos contenidos, procedimientos y principios explicativos gozaron del beneplácito de los superiores de la Compañía de Jesús.

Los procedimientos de investigación y difusión de datos climáticos se revistieron de un carácter homogéneo y se aplicaron por igual en todos los territorios donde hicieron acto de presencia los jesuitas. Puesto que no presentaban problemas de comprensión para sus usuarios, fueron pública y habitualmente compartidos por éstos. Además, propiciaron la conformación de regularidades y comparaciones climáticas. Acaso esta circunstancia podría haberse visto reforzada si se hubiese generalizado la recogida de datos atmos-

\footnotetext{
81 Ibidem: 75.

82 Burriel, 1757: 42-45.
} 
féricos con instrumentos meteorológicos y consignado los registros en tablas; pues la evidencia de las cantidades numéricas otorgaría más fiabilidad y uniformidad al discurso científico y coadyuvaría a mostrar inequívocamente las concordancias y los sesgos de las observaciones. A falta de suficientes casos documentados acerca de esta práctica entre las filas de los jesuitas, tal vez habría que buscar en las obras de sus herederos intelectuales y en las de otros colectivos que operaron en la América española (expedicionarios, médicos, militares, funcionarios, redactores de prensa, etc.) más ejemplos significativos.

\section{BiBLIOGRAFÍA}

Acosta, José, Historia Natural y Moral de las Indias, en que se tratan las cosas notables del Cielo, elementos, metales, plantas y animales de ellas; y los ritos, ceremonias, leyes y gobierno y guerras de los Indios, 1590.

Acuña, Cristóbal de, Nuevo descubrimiento del gran río de las Amazonas, 1641.

Aguirre, Emiliano, "Una hipótesis evolucionista en el siglo XVI. El padre Acosta y el origen de las espacies americanas", Arbor, 37 (Madrid, 1957): 176-187.

Alegre, Francisco Xavier, Historia de la Provincia de la Compañía de Jesús en Nueva España, 1842.

Álvarez Peláez, Raquel, "La historia natural en los siglos XVI y XVII", Alejandro Díez Torre et al., La ciencia Española en Ultramar. Actas de las I Jornadas sobre España y las expediciones científicas en América y Filipinas, Madrid, Doce Calles, 1991: 79-95.

Angelis, Pedro de, Colección de obras y documentos relativos a la historia antigua y moderna de las provincias del Río de la Plata, Buenos Aires, 1836.

Blasco, Amparo, La Meteorología en el Descubrimiento, Madrid, Instituto Nacional de Meteorología, 1987.

Barco, Miguel del, Historia Natural y Crónica de la Antigua California, 1767.

Broc, Numa, La Géographie des Philosophes, Géographes et Voyageurs français au XVIIIe Siècle, París, Ophyris, 1971.

Burriel, Andrés Marcos, Noticias de la California y de su Conquista Temporal y Espiritual hasta el Tiempo Presente, 1757.

Camaño Bazán, José, Noticia del Gran Chaco, 1778.

Capel, Horacio, La fisica sagrada. Creencias religiosas y teorías científicas en los orígenes de la geomorfología española. Siglos XVII-XVIII, Barcelona, El Serbal, 1983. 
Capel, Horacio, "Ramas en el árbol de la ciencia: geografía, física e historia natural en las expediciones náuticas del siglo XVIII", Alejandro Díez Torre et al, De la Ciencia Ilustrada a la Ciencia Romántica. Actas de las II Jornadas sobre "España y las expediciones científicas en América y Filipinas”, Madrid, Ateneo de Madrid, Doce Calles, 1995: 503-536.

Capel, Horacio, "Medicina y clima en la España del siglo XVIII", Revista de Geografía, XXXII-XXXIII (Barcelona, 1998-1999): 79-105.

Carolino, Luís Miguel, História, Naturaleza e Conhecimento na Cosmovisao Profética de António Viera, Millones Figueroa, Luis y Ledezma, Domingo (eds.), El saber de los jesuitas, historias naturales y el Nuevo Mundo, Madrid, Iberoamericana, 2005: 85-108.

Casanueva, F., "Félix Gómez de Vidaurre: un jesuita expulso, chileno y patriota", Manfred Tietz (ed.), Los jesuitas españoles expulsos. Su imagen y su contribución al saber sobre el mundo hispánico en la Europa del siglo XVIII, Madrid, Iberoamericana, 2001: 207-235.

Clavijero, Francisco Xavier, Historia de la Antigua o Baja California, 1757.

Clavijero, Francisco Xavier, Historia Antigua de México, 1780.

Cobo, Bernabé, Historia del Nuevo Mundo, 1653.

Díez Torre, Alejandro et al., La Ciencia Española en Ultramar. Actas de las I Jornadas sobre España y las expediciones científicas en América y Filipinas, Madrid, Doce Calles, 1991.

Egaña, Antonio, Historia de la Iglesia en la América Española desde su descubrimiento hasta los comienzos del siglo XIX. Madrid, Biblioteca de Autores Españoles, 1966.

Falkner, Thomas, Derrotero desde la ciudad de Buenos Aires hasta la de los Césares, que por otro nombre llaman la Ciudad Encantada, 1760.

Falkner, Thomas, Descripción de Patagonia y de las partes adyacentes de la América Meridional. Que contiene una razón del suelo, producciones, animales, valles, montañas, ríos, lagunas, etc., de aquellos países. La religión, gobierno, política, costumbres y lenguas de sus moradores, con algunas particularidades relativas a las islas Malvinas, 1774.

Feingold, Mordechai (ed.), Jesuit Science and the Republic of Letters, Cambridge, Massachusetts, The MIT Press, 2003.

Feldhay, Rivka, The Cultural Field of Jesuit Science, en O'Malley, John (ed.), The Jesuits: Cultures, Sciences, and the Arts, 1540-1773, Toronto, University of Toronto Press, 1999: 107-130.

Feldman, Theodore, The history of Meteorology, 1750-1800: a study in the quantification of experimental Physics, Berkeley, University of California, 1983. 
Feldman, Theodore, "The Ancient Climate in the Eighteenth and Early Nineteenth century", Michael Shortland, Science and Nature: Essays in the History of the Environmental Sciences, Stanford in the Vale, British Society for the History of Science, 1993: 23-40.

Furlong, Guillermo, Naturalistas argentinos durante la dominación hispánica, Buenos Aires, Huarpes, 1948.

Furlong, Guillermo, Los jesuitas y la cultura rioplatense, Buenos Aires, Biblos, 1994.

García Hourcade, Juan Luis, La meteorología en la España Ilustrada y la obra de Vicente Alcalá Galiano, Segovia, Biblioteca de Ciencia y Artillería, 2002: 100132.

Gerbi, Antonello, La disputa del Nuovo Mundo. Storia di una polemica: 1750-1900, Milán-Nápoles, Riccardo Ricciardi Editore, 1955.

Gili, Felipe Luis, Observaciones fitológicas sobre algunas plantas exóticas introducidas en Roma, 1789.

Glacken, Clarence, Traces on the Rodian Shore: Nature and Culture in Western Thought from Ancient Times to the End of the Eighteenth Century, Berkeley, University of California Press, 1967.

Gómez de Vidaurre y Girón, Félix, Historia geográfica, natural y civil del Reino de Chile, 1789.

Greer, Allan, "The Exchange of Medical Knowledge between Natives and Jesuits in New France", Luis Millones Figueroa, y Domingo Ledezma (eds.), El saber de los jesuitas, historias naturales y el Nuevo Mundo, Madrid, Iberoamericana, 2005: $135-146$.

Guevara, José, Historia del Paraguay, Río de la Plata y Tucumán en la Historia de la Compañía de Jesús en la Provincia del Paraguay, 1764.

Guijarro Mora, Víctor, "El barómetro y los proyectos meteorológicos de la Ilustración: el caso español”, Endoxa: Series Filosóficas, 19 (Madrid, 2005): 159-190.

Guijarro Mora, Víctor y González de la Lastra, Leonor, La quimera del autómata matemático, Madrid, Cátedra, 2010.

Gumilla, José, El Orinoco ilustrado. Historia natural, civil, y geográphica de este gran río, y de sus caudalosas vertientes. Gobierno, usos, y costumbres de los indios sus habitantes, con nuevas, y útiles noticias de Animales, Árboles, Frutos, Aceytes, Resinas, Yervas, y Raíces medicinales. Y sobre todo, se hallarán conversiones muy singulares à nuestra Santa Fe, y casos de mucha edificación, 1745.

Harris, Steven, "Transporting the Merton Thesis: Apostolic Spirituality and the Establishment of the Jesuit Scientific Tradition", Science in Context, 3/1 (Leiden, 1989): 29-65. 
Harris, Steven, "Confession Building, Long-Distance Networks, and the Organization of Jesuit Science", Early Science and Medicine, 1 (Leiden, 1996): 287-318.

Harris, Steven, "Mapping the Jesuit Science: The Role of Travel in the Geography of Knowledge", John O'Malley (ed.), The Jesuits: Cultures, Sciences, and the Arts, 1540-1773, Toronto, University of Toronto Press, 1999: 212-240.

Hermosilla, Ignacio de, "Censura a la Historia de la California, del padre Andrés Marcos Burriel", Boletín de la Real Academia de la Historia, 52 (Madrid, 1908): 413-415.

Huffine, Kristin, "Raising Paraguay From Decline: Memory, Ethnography, and Natural History in the Eighteenth-Century Accounts of the Jesuits Fathers, en Millones Figueroa, Luis, La intelligentsia jesuita y la naturaleza del Nuevo Mundo en el siglo XVII", Luis Millones Figueroa y Domingo Ledezma (eds.), El saber de los jesuitas, historias naturales y el Nuevo Mundo, Madrid, Iberoamericana, 2005: 279-302.

Iglesias, María del Carmen, El pensamiento de Montesquieu, Madrid, Alianza Editorial, 1984.

Iturri, Francisco, Carta Crítica sobre la Historia de América del señor D. Juan Bautista Muñoz, 1798.

Jankovic, Vladimir, Reading the Skies: A Cultural History of the English Weather, 1650-1820, Manchester, Manchester University Press, 2000.

Juárez, Gaspar, Noticias Fitológicas, 1789.

Lafuente, Antonio y Sala Catalá, José (eds.), Ciencia colonial en América, Madrid, Alianza Universidad, 1992.

Lafuente, Antonio y López-Ocón Cabrera, Leoncio, "Tradiciones científicas y expediciones ilustradas en la América hispana del siglo XVIII", Juan José Saldaña (coord.), Historia social de la ciencia en América Latina, México, UNAM/Porrúa, 1996: 247-281.

Leclerc, Joseph-Louis, Histoire Naturelle Générale et Particulliére, 1749.

Ledezma, Domingo y Millones Figueroa, Luis, "Introducción: los jesuitas y el conocimiento de la naturaleza americana", Luis Millones Figueroa, y Domingo Ledezma (eds.), El saber de los jesuitas, historias naturales y el Nuevo Mundo, Madrid, Iberoamericana, 2005: 9-26.

Lüdecke, Cornelia, "East Meets West: Meteorological Interests of the Moravians in Greenland and Labrador since the 18th Century". History of Meteorology, 2 (Waterville, Maine, 2005): 123-32.

Maroni, Pablo, Noticias Auténticas del Famoso Río Marañón y Misión Apostólica de la Compañía de Jesús de la Provincia de Quito en los Dilatados Bosques de dicho Río, 1738. 
Meier, Johannes, "Los jesuitas expulsados de Chile (1767-1839), sus itinerarios y sus pensamientos", Manfred Tietz (ed.), Los jesuitas españoles expulsos. Su imagen y su contribución al saber sobre el mundo hispánico en la Europa del siglo XVIII, Madrid, Iberoamericana, 2001: 423-441.

Middleton, William Edgar Knowles, A History of the Theories of Rain and other Forms of Precipitation, Nueva York, Franklin Watts, 1965.

Middleton, William Edgar Knowles, Invention of the Meteorological Instruments, Baltimore, Johns Hopkins Press, 1969.

Millones Figueroa, Luis y Ledezma, Domingo (eds.), El saber de los jesuitas, historias naturales y el Nuevo Mundo, Madrid, Iberoamericana, 2005.

Millones Figueroa, Luis, "La intelligentsia jesuita y la naturaleza del Nuevo Mundo en el siglo XVII", Luis Millones Figueroa y Domingo Ledezma (eds.), El saber de los jesuitas, historias naturales y el Nuevo Mundo, Madrid, Iberoamericana, 2005: 27-47.

Molina, Juan Ignacio, Compendio de la Historia Geográfica, Natural y Civil del Reyno de Chile, 1776-1787.

Muñoz Pérez, José, "Los historiadores primitivos de Indias y el pensamiento geográfico”, Fernando de Solano y Fermín del Pino, América y la España del siglo XVI, Madrid, CSIC, 1982, vol. I: 135-188.

Navia Méndez-Bonito, Silvia, "Las historias naturales de Francisco Javier Clavijero, Juan Ignacio de Molina y Juan de Velasco", Luis Millones Figueroa y Domingo Ledezma (eds.), El saber de los jesuitas, historias naturales y el Nuevo Mundo, Madrid, Iberoamericana, 2005: 225-250.

O’Malley, John (ed.), The Jesuits: Cultures, Sciences, and the Arts, 1540-1773, Toronto, University of Toronto Press, 1999.

O’Malley, John, "The historiography of the Society of Jesus", John O'Malley (ed.), The Jesuits: Cultures, Sciences, and the Arts, 1540-1773, Toronto, University of Toronto Press, 1999: 3-37.

Ovalle, Diego Alonso de, Histórica Relación del Reyno de Chile, 1646.

Pauw, Cornelio de, Recherches philosophiques sur les Américains, 1768.

Pino, Fermín del, "La Historia natural y moral de las Indias como género: orden y génesis literaria de la obra de Acosta”, Histórica, XXIV/2 (Lima, 2000): 295-326.

Ponce Leiva, Pilar, 1992, "Burocracia colonial y territorio americano: las Relaciones de Indias", Antonio Lafuente, y José Sala Catalá (eds.), Ciencia colonial en América, Madrid, Alianza Universidad, 1992: 29-33.

Quiroga, José, Descripción del Río Paraguay, 1753.

Raynal, Guillaume-Thomas-François, Histoire philosophique et politique des establissements des Européens dans les deux Indes, 1775. 
Robertson, William, The History of America, 1777.

Rojas, Silvestre Antonio de, Derrotero de un viaje desde Buenos Aires a los Césares, por el Tandil y el Volcán, rumbo de sud-oeste, comunicado a la Corte de Madrid, en 1707, por Silvestre Antonio de Rojas, que vivió muchos años entre los indios Pehuenches, 1707.

Sainz Ollero, Héctor et al., José Sánchez Labrador y los naturalistas jesuitas del Río de la Plata, Madrid, Monografías de la Dirección General de Medio Ambiente, Ministerio de Obras Públicas y Urbanismo, 1989.

Saldaña, Juan José (coord.), Historia social de las ciencias en la América latina, México, UNAM-Porrúa, 1996.

Sánchez Labrador, José, Paraguay Católico, 1769.

Sánchez Labrador, José, Paraguay Natural, 1771-1776.

Sargent, Frederick, Hippocratic Heritage, a History of Ideas about Weather and Human Health, Nueva York, Pergamon Press, 1982.

Shapin, Steven, La Revolución Científica. Una interpretación alternativa, Barcelona, Paidós, 2000.

Shortland, Michael, Science and Nature: Essays in the History of the Environmental Sciences, Stanford in the Vale, British Society for the History of Science, 1993.

Solano, Fernando de y Pino, Fermín del, América y la España del siglo XVI, Madrid, CSIC, 1982, vol. I.

Tietz, Manfred (ed.), Los jesuitas españoles expulsos. Su imagen y su contribución al saber sobre el mundo hispánico en la Europa del siglo XVIII, Madrid, Iberoamericana, 2001.

Torales Pacheco, María Cristina, "Los jesuitas novohispanos y la naturaleza en el siglo XVIII", Luis Millones Figueroa y Domingo Ledezma (eds.), El saber de los jesuitas, historias naturales y el Nuevo Mundo, Madrid, Iberoamericana, 2005: 195-224.

Torres, Diego de, Relación de la provincia del Perú, 1603.

Urteaga, Luis, "La teoría de los climas y los orígenes del ambientalismo", Geo Crítica, 99 (Barcelona, 1992). http://www.ub.edu/geocrit/geo99.htm (Fecha de consulta 29/09/2014). ISSN: 0210-0754.

Valverde Pérez, Nuria, Actos de precisión. Instrumentos científicos, opinión pública y economía moral en la Ilustración española, Madrid, CSIC, 2007.

Vargas Alquicira, Susana, La singularidad novohispana en los jesuitas del siglo XVIII, México, Universidad Nacional Autónoma de México, 1989.

Velasco, Juan de, Historia del Reino de Quito, 1789. 
Venegas, Miguel, Noticia de la California y de su conquista temporal y espiritual hasta el tiempo presente, 1757.

Fecha de recepción: 9 de marzo de 2013.

Fecha de aceptación: 4 de julio de 2013.

\section{Jesuits' Climatologic Knowledge in Spanish America. Eighteenth Century}

Jesuits settled in the New World from the moment it was discovered. They participated in numerous tasks related to geographical and naturalist research and they showed interest in the descriptions, comparisons and praises of American climates. In this regard, they undertook a series of actions so as to obtain, handle and transmit climatic information, based on direct observation of phenomena, follow up of prestigious literary models, as well as internal communication.

KEY WORDS: climate; climatic information; Jesuits; qualitative and quantitative observations; natural and moral history. 